Supporting information

\title{
Rate Enhancement of Acid-catalyzed Alcohol Dehydration by Supramolecular Organic Capsules
}

Wei Zhang, ${ }^{1}$ Guanhua Cheng, ${ }^{1}$ Gary L. Haller, ${ }^{1}$ Yue Liu, ${ }^{1 *}$ and Johannes A. Lercher ${ }^{1,2 *}$

${ }^{1}$ Department of Chemistry and Catalysis Research Center, Technical University of Munich, Lichtenbergstrasse 4, 85748 Garching, Germany.

${ }^{2}$ Institute for Integrated Catalysis, Pacific Northwest National Laboratory P.O. Box 999, Richland, Washington 99352, USA.

Corresponding Authors: Yue Liu, Email: yue.liu@tum.de; Johannes A. Lercher, Email:

johannes.lercher@ch.tum.de 


\section{Experimental Procedures}

Resorcinarene synthesis: Resorcinol (15 g) was added into $75 \mathrm{~mL}$ ethanol containing $19 \mathrm{~mL}$ $37 \%$ aqueous $\mathrm{HCl}$ and stirred on ice for $15 \mathrm{~min}$. Dodecanal $(30 \mathrm{~mL})$, solved in $39 \mathrm{~mL}$ ethanol was slowly added into resorcinol solution on ice in about $30 \mathrm{~min}$. After warm up to room temperature, the reaction mixture was refluxed at $110 \mathrm{oC}$ for $23 \mathrm{~h}$. When the reaction mixture was cooled to room temperature, $150 \mathrm{~mL}$ cold methanol was added, and the precipitation was filtered and washed with $150 \mathrm{~mL}$ methanol. The solid was recrystallized with $95 \mathrm{~mL}$ methanol, and light yellow resorcinarene was obtained after remove remaining trace amount of methanol by vacuum dry. Resorcinarene structure is confirmed by NMR spectroscopy.

Resorcinarene capsule: Trace amount $\mathrm{HCl}$ in $\mathrm{CDCl}_{3}$ was removed by $\mathrm{Al}_{2} \mathrm{O}_{3}$ before use. 63.3 $\mathrm{mM}$ resorcinerane was solved in water saturated $\mathrm{CDCl}_{3}$ as stock solution.

Cyclohexanol/Cyclohexene encapsulation in Capsule: Specific concentration of cyclohexanol or cyclohexene was added into $3.3 \mathrm{mM}$ capsule solution in water saturated $\mathrm{CDCl}_{3}$ at room temperature with or without $32 \mathrm{mM} \mathrm{HCl}$, and the mixture were measured by NMR. Tetraethylsilane was used as internal standard for Cyclohexanol encapsulation. The encapsulated cyclohexanol was obtained from the total amount of cyclohexanol minus the remaining free cyclohexanol. Diffusion Ordered Spectroscopy (DOSY) of resorcinarene capsule (3.3mM) and cyclohexanol $(19.8 \mathrm{mM})$ with $32 \mathrm{mM} \mathrm{HCl}$ was recorded with a Bruker Avance HD 400 spectrometer using the Bruker standard DOSY routine.

Resorcinarene capsule catalyzed cyclohexanol dehydration: Cyclohexanol (3.3 mM, 6.6 mM, $13.2 \mathrm{mM}$ or $19.8 \mathrm{mM}$ ) was added into $\mathrm{D}_{2} \mathrm{O}$ saturated $\mathrm{CDCl}_{3}$ containing $3.3 \mathrm{mM}$ capsule and 32 $\mathrm{mM} \mathrm{HCl}$ (unless else mentioned) with a total volume of $2.5 \mathrm{~mL}$. The reaction was performed in 
pressure tube under stirring at 318K, 323K, 328K, 333K. Products were measured by NMR with resorcinarene as internal standard.

$\mathrm{HCl}$ catalyzed cyclohexanol dehydration: Cyclohexanol $(0.075 \mathrm{M}, 0.15 \mathrm{M}$ or $0.3 \mathrm{M})$ was added into $\mathrm{D}_{2} \mathrm{O}$ saturated $\mathrm{CDCl}_{3}$ containing $0.15 \mathrm{M}$ aqueous $\mathrm{HCl}$ and $0.1 \mathrm{~mL} \mathrm{D}_{2} \mathrm{O}$ (unless else mentioned) with a total volume of $4 \mathrm{~mL}$. The reaction was performed in pressure tube under stirring at $388 \mathrm{~K}, 398 \mathrm{~K}$ or $408 \mathrm{~K}$. Products were measured by NMR with tetraethylsilane as internal standard.

Zeolites catalyzed cyclohexanol dehydration: Cyclohexanol (9.6 mM, $19.2 \mathrm{mM}, 28.8 \mathrm{mM}$ or $38.4 \mathrm{mM}$ ) was added into $\mathrm{D}_{2} \mathrm{O}$ saturated $\mathrm{CDCl}_{3}$ containing $23 \mathrm{mg}$ water saturated zeolites (HBEA, $\mathrm{Si} / \mathrm{Al} 75)$ with a total volume of $4 \mathrm{~mL}$. The reaction was performed in pressure tube under stirring at $333 \mathrm{~K}, 343 \mathrm{~K}, 353 \mathrm{~K}$. Products were measured by NMR with tetraethylsilane as internal standard.

Adsorption of cyclohexanol from chloroform solutions into HBEA: Cyclohexanol in chloroform (5-400 mM) was mixed with HBEA (10 mg, $20 \mathrm{mg}$ or $30 \mathrm{mg})$ in a final volume of 1.5 $\mathrm{mL}$ and stirred for minimum $24 \mathrm{~h}$ at $284 \mathrm{~K}, 297 \mathrm{~K}$ or $308 \mathrm{~K}$. The remaining cyclohexanol was detected with gas chromatography after filtration. 


\section{Supporting Figures and Tables}

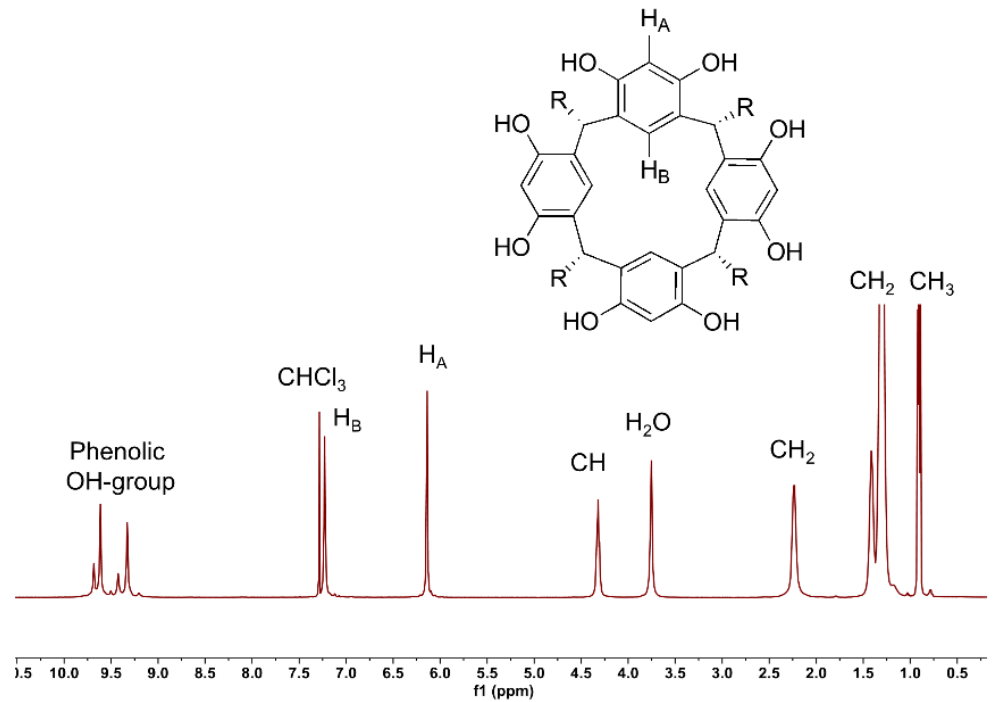

Figure S1. NMR spectroscopy of resorcinarene capsule in d-chloroform.

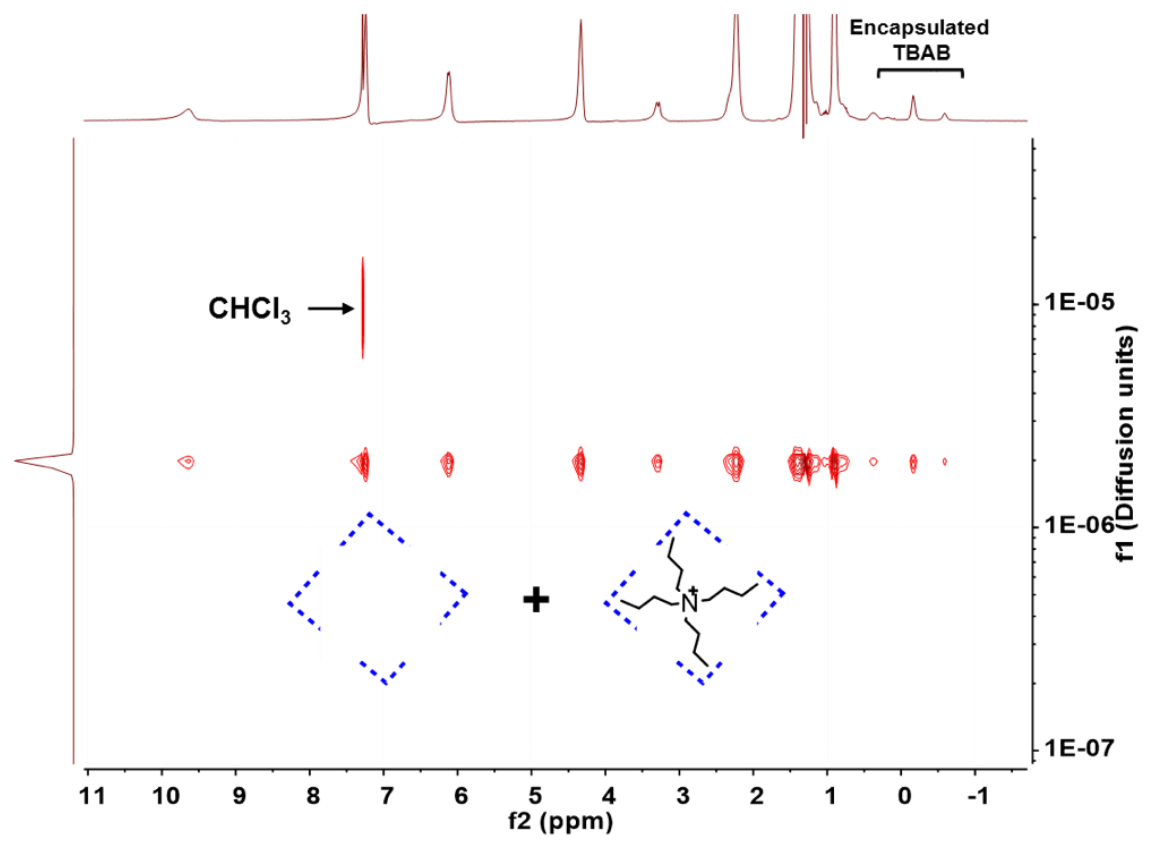

Figure S2. Diffusion Ordered Spectroscopy (DOSY) of resorcinarene capsule and TBAB. 
A)
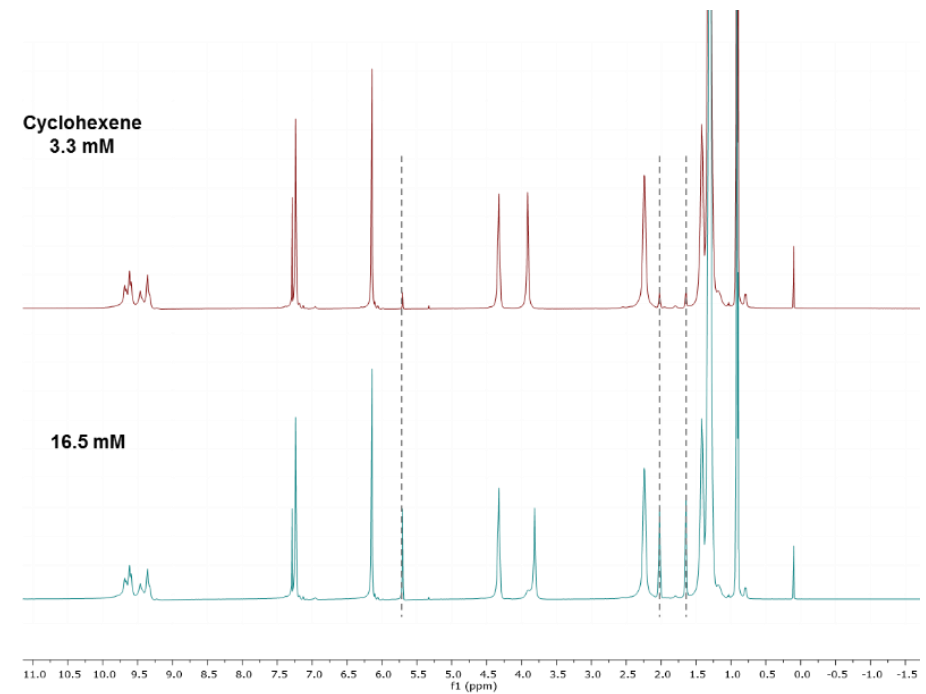

B)

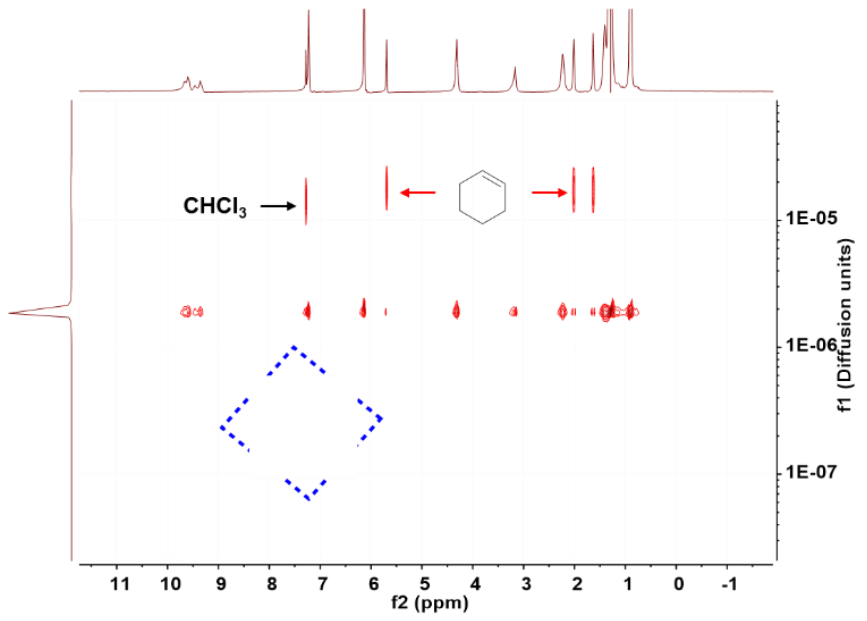

Figure S3. (A) NMR spectroscopy of different concentration of cyclohexene with $3.3 \mathrm{mM}$ resorcinarene capsule in d-chloroform. Black dot line refers to free cyclohexene peaks. (B) Diffusion Ordered Spectroscopy (DOSY) of resorcinarene capsule and cyclohexene.

(Figure Note) The peaks of phenolic OH group in Figure S3A (chemical shifts between 9-10) is sharp peaks compared to the broad peaks of the counterparts in Figure 1A in the maintext. This is because the presence of $\mathrm{HCl}$ in Figure 1A induced fast proton exchange with the phenolic $\mathrm{OH}$, broadening the NMR signal. 


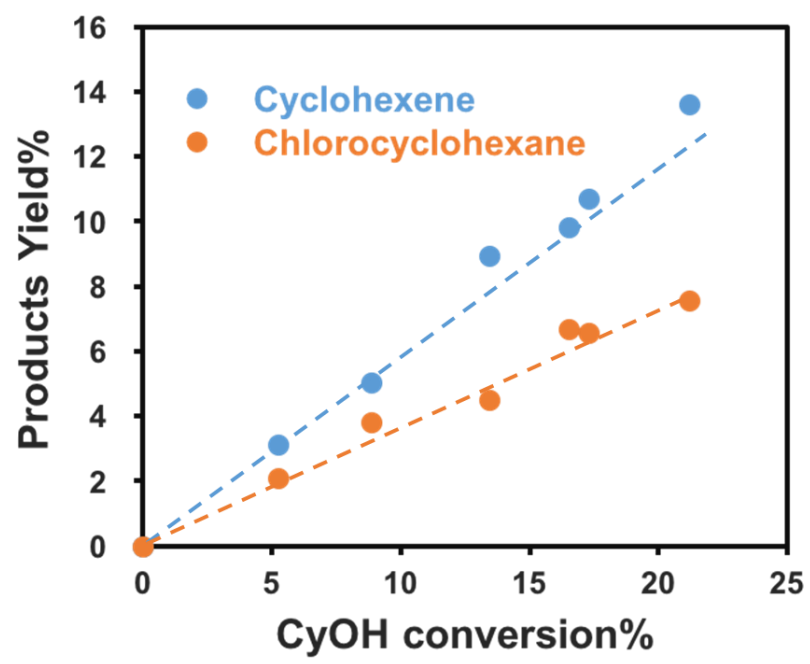

Figure S4. Yield of cyclohexene and chlorocyclohexane as a function of cyclohexanol conversion catalyzed by $\mathrm{HCl}(150 \mathrm{mM} \mathrm{HCl}, 300 \mathrm{mM}$ cyclohexanol, $408 \mathrm{~K})$.

(Figure Note) The linear increase of both yields of cyclohexene and chlorocyclohexane at low conversion of cyclohexanol indicates that both products are generated directly from the reaction of cyclohexanol dehydration.

\section{Derivations of rate equations:}

Reaction elementary steps includes hydronium ion binding into the capsule with equilibrium constant $K_{\mathrm{H}}{ }^{\circ}(\mathrm{Rxn} \mathrm{S1})$, cyclohexanol encapsulation into the capsule with equilibrium constant $K_{\mathrm{en}}{ }^{\circ}$ (Rxn S2) and dehydration step with rate constant k (Rxn S3).

$$
\begin{aligned}
& \mathrm{H}^{+}\left(\mathrm{H}_{2} \mathrm{O}\right)_{n}+\text { Capsule } \stackrel{K_{\mathrm{H}^{\circ}}^{\circ}}{-} \mathrm{H}^{+}\left(\mathrm{H}_{2} \mathrm{O}\right)_{n} \cdots \text { Capsule } \\
& \mathrm{C}_{6} \mathrm{H}_{11} \mathrm{OH}+\text { Capsule } \stackrel{K_{\text {en }}^{\circ}}{-}=\mathrm{C}_{6} \mathrm{H}_{11} \mathrm{OH} \cdots \text { Capsule } \\
& \mathrm{C}_{6} \mathrm{H}_{11} \mathrm{OH} \cdots \text { Capsule } \cdots \mathrm{H}^{+}\left(\mathrm{H}_{2} \mathrm{O}\right)_{n} \stackrel{k}{\longrightarrow} \mathrm{C}_{6} \mathrm{H}_{10}+\mathrm{H}_{2} \mathrm{O}+\text { Capsule }
\end{aligned}
$$

(Rxn S3) 
Cyclohexanol encapsulation degree is denoted as $\theta_{\mathrm{Cy}}$ and cyclohexanol free capsule is 1 - $\theta_{\mathrm{Cy}}$; degree of capsule with hydronium ion is $\theta_{\mathrm{H}}$, then the capsule without hydronium ion is $1-\theta_{\mathrm{H}}$. The cyclohexanol and hydronium ion concentration in the bulk solution are denoted as $[\mathrm{Cy}]$ and $\left[\mathrm{H}_{3} \mathrm{O}^{+}\right]$ respectively. The quasi-equilibrium of Rxn S1 and S2 give

$$
\begin{gathered}
K_{\mathrm{en}}^{\circ}=\frac{\theta_{\mathrm{Cy}}}{[\mathrm{Cy}]\left(1-\theta_{\mathrm{Cy}}\right)} \\
K_{\mathrm{H}}^{\circ}=\frac{\theta_{\mathrm{H}}}{\left[\mathrm{H}_{3} \mathrm{O}^{+}\right]\left(1-\theta_{\mathrm{H}}\right)}
\end{gathered}
$$

which further give the expression of $\theta_{\mathrm{Cy}}$ and $\theta_{\mathrm{H}}$ as

$$
\begin{aligned}
& \theta_{\mathrm{Cy}}=\frac{K_{\mathrm{e}}^{\circ}[\mathrm{Cy}]}{1+K_{\mathrm{en}}^{\circ}[\mathrm{Cy}]} \\
& \theta_{\mathrm{H}}=\frac{K_{\mathrm{H}}^{\circ}\left[\mathrm{H}_{3} \mathrm{O}^{+}\right]}{1+K_{\mathrm{H}}^{\circ}\left[\mathrm{H}_{3} \mathrm{O}^{+}\right]}
\end{aligned}
$$

The reaction rate $(r)$ is proportional to $\theta_{\mathrm{Cy}}, \theta_{\mathrm{H}}$ and capsule concentration [Cap]:

$$
r=k[\mathrm{Cap}] \theta_{\mathrm{Cy}} \theta_{\mathrm{H}}=k[\mathrm{Cap}] \cdot \frac{K_{\mathrm{en}}^{\circ}[\mathrm{Cy}]}{1+K_{\mathrm{en}}^{\circ}[\mathrm{Cy}]} \cdot \frac{K_{\mathrm{H}}^{\circ}\left[\mathrm{H}_{3} \mathrm{O}^{+}\right]}{1+K_{\mathrm{H}}^{\circ}\left[\mathrm{H}_{3} \mathrm{O}^{+}\right]}
$$

Equation S5 is the Equation 1 in the maintext.

Reformulating Equation S5 into Equation S6 shows that under constant $\left[\mathrm{H}_{3} \mathrm{O}^{+}\right]$the $1 / r$ increases linearly with $1 /[\mathrm{Cy}]$. In particular, the ratio of intercept to slope is $K_{\mathrm{en}}{ }^{\mathrm{o}}$. The experiment data show good agreement with Equation S6 (Figure S5) and the regressed values of $K_{\mathrm{en}}{ }^{\mathrm{o}}$ are in Table 1.

$$
\frac{1}{r}=\frac{1}{k[\mathrm{Cap}]} \cdot \frac{1+K_{\mathrm{H}}^{\circ}\left[\mathrm{H}_{3} \mathrm{O}^{+}\right]}{K_{\mathrm{H}}^{\circ}\left[\mathrm{H}_{3} \mathrm{O}^{+}\right]}+\frac{1}{k[\mathrm{Cap}]} \cdot \frac{1+K_{\mathrm{H}}^{\circ}\left[\mathrm{H}_{3} \mathrm{O}^{+}\right]}{K_{\mathrm{H}}^{\circ}\left[\mathrm{H}_{3} \mathrm{O}^{+}\right]} \cdot \frac{1}{K_{\mathrm{en}}^{\circ}} \cdot \frac{1}{[\mathrm{Cy}]}
$$

With the obtained $K_{\text {en }}{ }^{\circ}$, the values of $k$ and $K_{\mathrm{H}}{ }^{\circ}$ are further determined by regression of $r$ with $\left[\mathrm{H}_{3} \mathrm{O}^{+}\right]$under constant $[\mathrm{Cy}]$ (see Figure 3B in the maintext). The results are compiled in Table 1. 

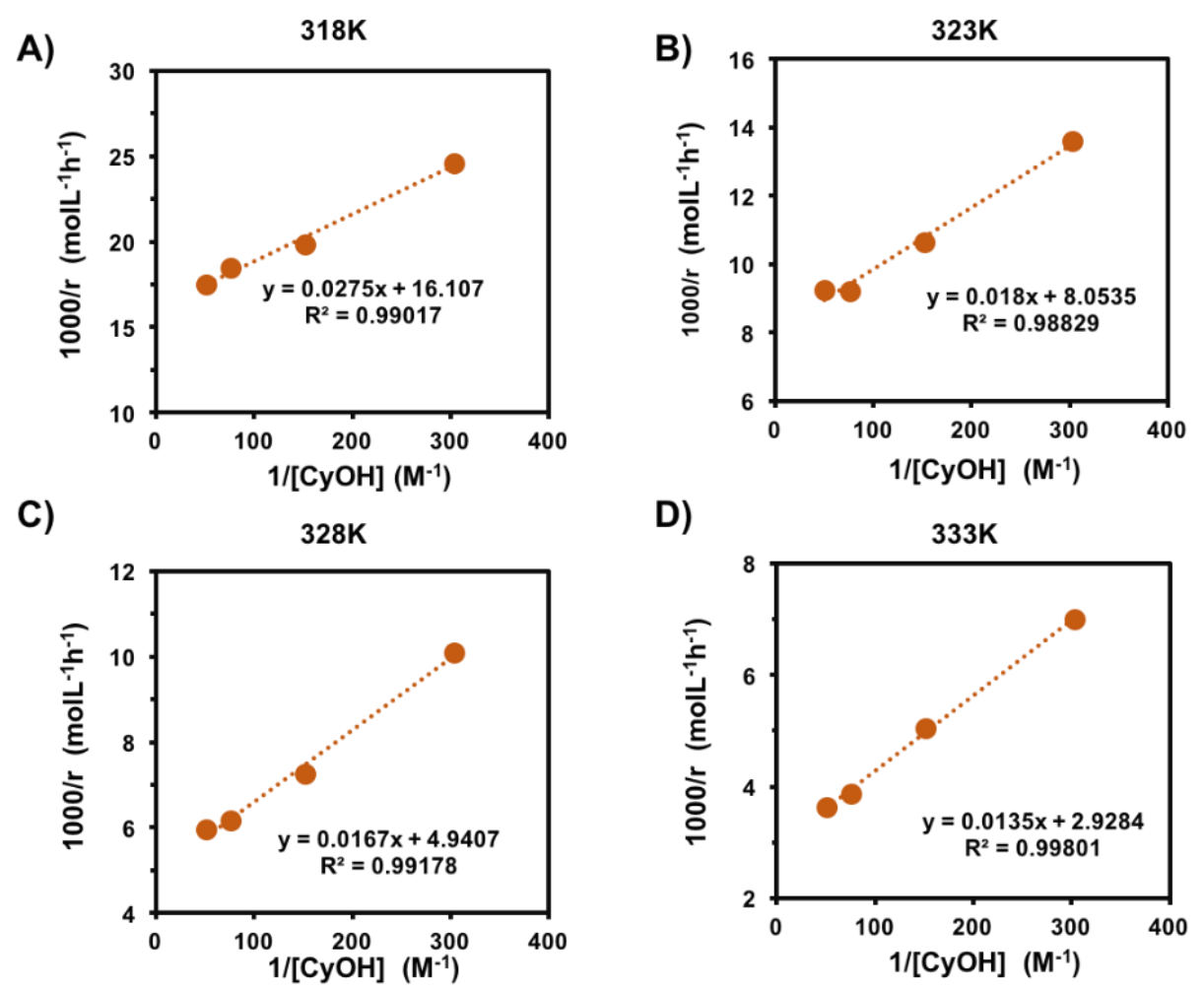

Figure S5. Regression of the measured reaction rate $(r)$ with cyclohexanol concentration [CyOH] in the formula of Equation S6 at $318 \mathrm{~K}$ (A), $323 \mathrm{~K}$ (B), $328 \mathrm{~K}$ (C) and $333 \mathrm{~K}$ (D).
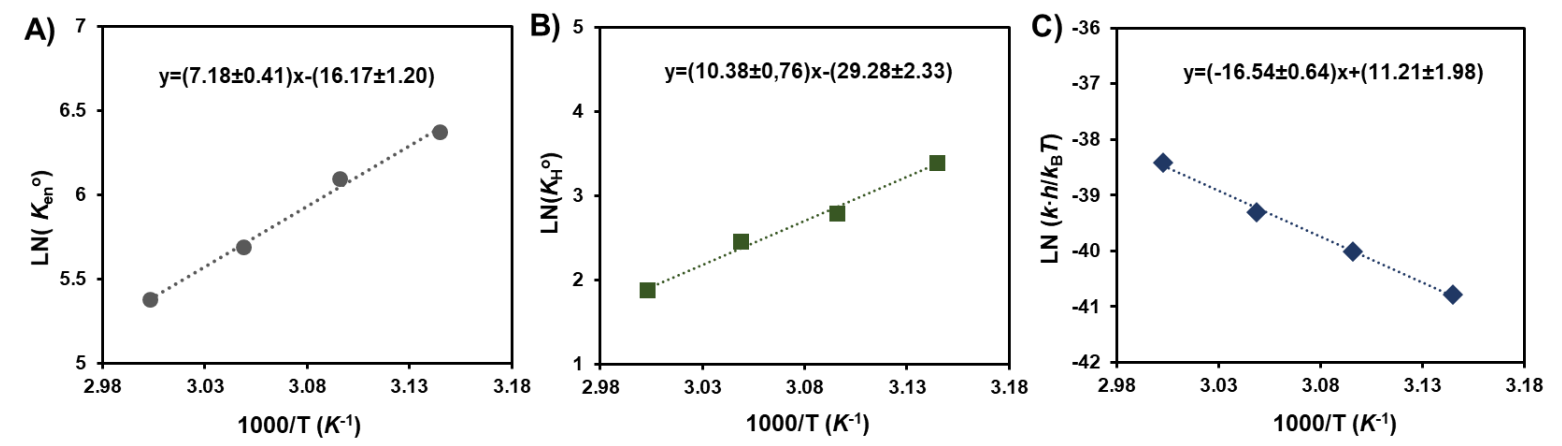

Figure S6. Van't Hoff plots of $K_{\text {en }}{ }^{\circ}(\mathrm{A}), K_{\mathrm{H}}{ }^{\mathrm{o}}$ (B) and Erying plot of $k(\mathrm{C})$. 

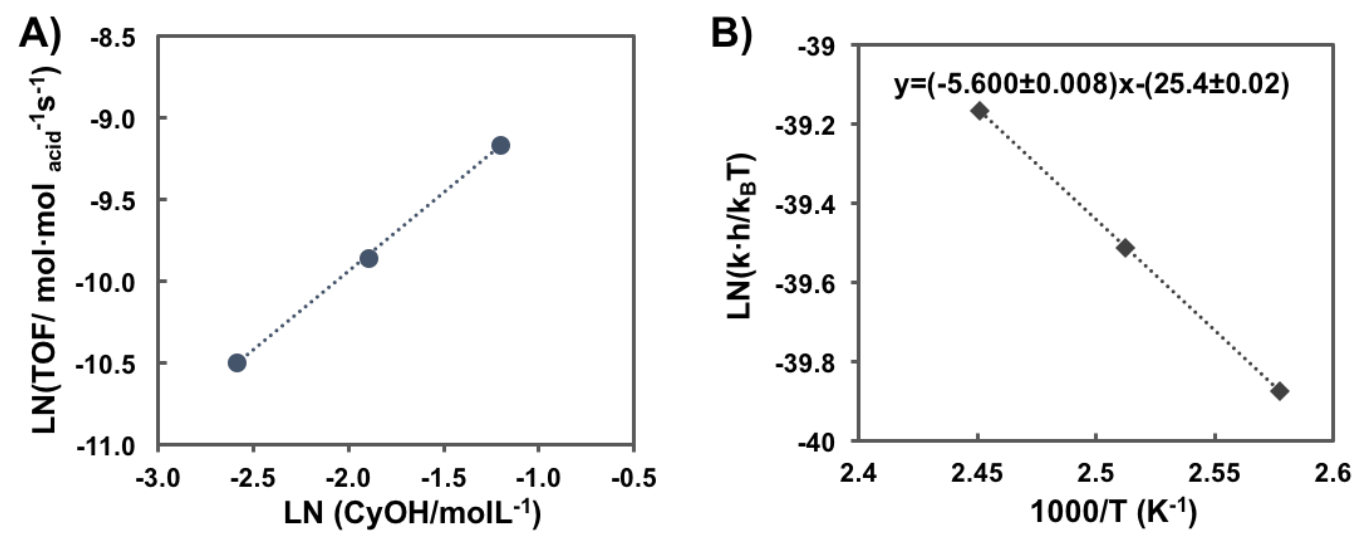

Figure S7. (A) TOF as a function of cyclohexanol concentration in its dehydration catalyzed by $\mathrm{HCl}$. (B) Erying plot of rate constant in this reaction.

A)

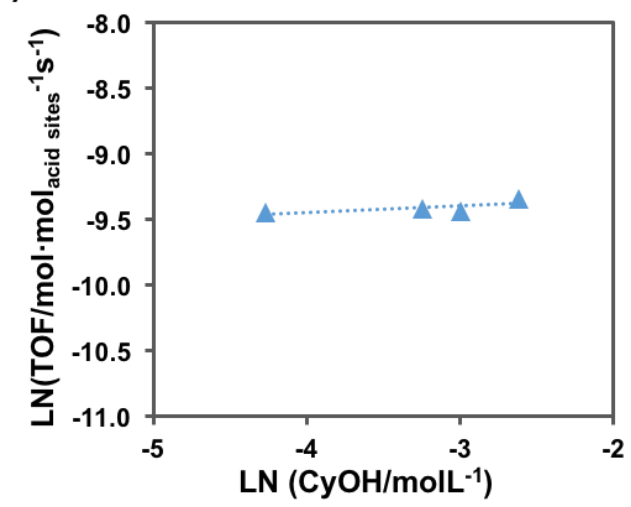

B)

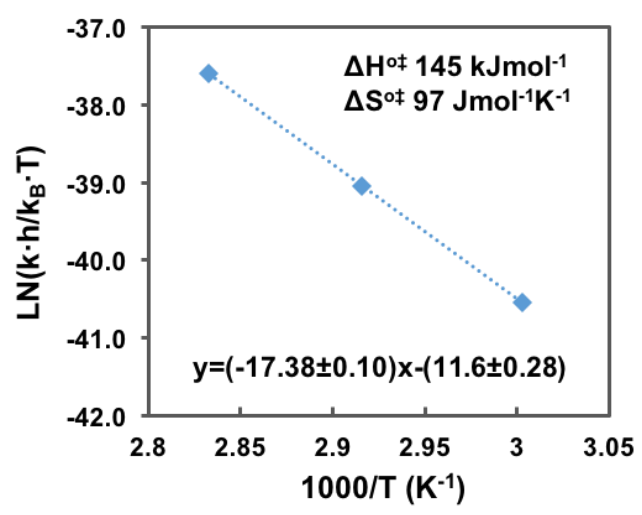

Figure S8. (A) TOF of cyclohexanol dehydration as a function of its concentration catalyzed by water saturated HBEA. (B) Erying plot of rate constant in this reaction. 